\title{
How Ontic Structural Realism would Formalize Scientific Progress
}

\begin{abstract}
By Alex B Pablos ${ }^{*}$
This essay tries to make a tangential cut between the debate that seeks the most adequate definition of scientific progress (involving authors such as K. Popper, T Kuhn, A Bird or J Saatsi) and the debate on the viability of structural realism to be considered the best epistemological approach to the understanding of nature (B van Fraassen, J Ladyman, J Worrall, S Psillos...). Thus, we will first connect both debates by showing that they shared a common problem before their progressive distancing. Finally, we will outline a formulation of scientific progress inferred from the structural realism approach; in particular, our definition will be based on J. Ladyman's proposal in Every Thing Must Go as we will emphasize that it also provides an answer to the aforementioned original problem. Our conclusion is that this formulation of scientific progress differs from the three main ones, namely, truthlikeness, problem-solving, and accumulation of knowledge. This fourth form is necessarily linked to a speculative approximation of reality. Moreover, we want to suggest that this fourth conception is articulated under the shadow of the ideas of CS Peirce.
\end{abstract}

Keywords: structural realism, scientific progress, J Ladyman, speculative realism

\section{Introduction}

"Truths are fecund only if bound together"

(H Poincaré, The value of science, 1905)

Philosophical discussions, clearly in analytical philosophy, become more concrete and ramified due to the limits imposed by the (justified) academic requirements of rigor and formality. This leads to the generation of a microcosmos of debate which, despite being influenced by what sounds in the corridors, are alien to what happens in the next room, even though they may share themes, objectives and concerns. In view of this, the present essay tries to make a tangential cut between two prominent debates in contemporary philosophy of science: on the one hand, the debate that seeks to offer the most accurate formalization of scientific progress (held by authors such as K Popper, T Kuhn, A Bird, J Saatsi...); and on the other, the discussion regarding if structural realism, that is to say, the consideration that scientific theories expose only the structural or relational character of reality, is the best epistemological approach to understanding nature (involving B van Fraassen, J Worrall, J Ladyman, S Psillos...).

For this, our first objective is to make explicit the shared problematic underlying the two debates that we are dealing with. We will try to make this clear

\footnotetext{
*Master Student, University of Osnabrück, Germany.
} 
by showing that their problematic goes hand in hand with a conception of what the term "realism" means in its particular philosophical context. But our purpose does not end here. This contextualization will help us to offer an outline of how structural realism would formalise scientific progress. And we hold that this formulation of scientific progress will differ from the three main ones, namely, truthlikeness, problem-solving, and accumulation of knowledge, considering this fourth formulation as "speculative". Moreover, as we will see, the definition of scientific progress for structural realism that we will give is based mainly on $\mathbf{J}$ Ladyman's position as set out together with D Ross in Every Thing Must Go (2007). Due to that, we are aware of generalizing, among other things, over Ladyman's (1998) accepted distinction between epistemological structural realism (ESR), or "restrictive structural realism" (Psillos 2001), which understands that what science can know about reality is its structure, and ontic structural realism (OSR), or "radical structuralism" (van Fraassen 2006), according to which nature is structure. But the reason for our generalization is precisely part of the exposition, where we will argue that Ladyman's general project to support OSR is still related to a fundamental problem also shared by the debate on scientific progress: how to deal with the existence of theoretical entities.

It should be clarified, then, that this essay does not seek to argue for or against structural realism, and especially not for or against Ladyman's positions. Nor will it attempt to offer our positions on the debates which will be mentioned here and which are still ongoing: such as the new formulations of truthlikeness, the appropriateness or not of ramseyfication for structural realism, or the feasibility of certain structural models for explaining certain phenomena suggested by quantum mechanics. Instead, what we are dealing with here is the "is" and not the "should" of structural realism. Thus, we would like to reflect the channel through which structural realism has taken place and with which, according to the argument that we will explain, it can offer a different formulation of scientific progress.

For this, the first part of this essay contextualizes the emergence of structural realism in a broader philosophical problematic shared with the debate on scientific progress; this context holds a characteristic meaning of the term "realism". Then, the next part shows that the firsts formulations of structural realism, namely syntactic and semantic ones, did not overcome the aforementioned problematic. The following two parts offer the key points with which Ladyman in Every Thing Must Go attempts to be an alternative to those problems by endorsing OSR. Finally, it is offered an outline of the definition of scientific progress inferred from Ladyman's structural realism which we consider as "speculative", partly indebted to Q Meillassoux. In these last two parts we will deal with the presence of CS Peirce's pragmatic ideas in Ladyman's project. 


\section{Discussion Context at the Beginnings of Structural Realism}

The history of thought shows that the term "realism" is equivocal, it didn't mean the same in the face of the problem of the realism of the universals in the Middle Ages, as it did in the face of the problem regarding the knowledge of the external world in Modernist-Illustration, as it did in the different artistic realisms... and neither does it have a univocal meaning in contemporary positions: real are the transcendental instances of experience for phenomenologists, real is the void that promotes the symbolic creation in Lacan and some postmodernist... But despite this plurality of meanings, it turns out that structural realism has not made explicit what it understands by "realism". However, it does so with "structure" as shown by its awareness of different approaches that have prioritised knowledge of the law-like aspect of nature over its substantive knowledge: neokantians of the Marburg School, H Poincaré, M Schlick, B Russell... . To that, my point is that by focusing on its concept of "realism" we will easily glimpse its connection with the debate on scientific progress.

Perhaps "structural realism" appears stated for the first time in Structural realism and the meaning of theoretical terms (1970) by G Maxwell, but in 1962 he already exposes the same ideas: science shows relational descriptions of phenomenal impressions (quoting P Feyerabend and Russell) and, moreover, we should not hold a distinction between the observable and the theoretical, as this distinction is contingent, that is, is an a posteriori distinction that could change together with our instrumental capacity (Maxwell 1962, p. 26). What we see in this G Maxwell's claim for the structural knowledge offered by science is an attempt of the late logical empiricism trying to overcome the problems of the preceding logicism, of which Kuhn is another direct reaction/escape. This more general problem, I maintain, is perfectly reflected in WVO Quine's Word and the Object (1960) regardless of its particular conclusions. In this work, Quine argues that all entities are theoretical (therefore his conventionalism). Science, as common sense, tends to inflate ontology (Quine 1951), but first order logic can clean and regiment scientific theories on bases that consider the whole set of theories (therefore his holism). With such rigour we can commit ourselves to the existence of theoretical entities (Quine 1960); that is, for Quine, there are "charm" quarks, but not tables, which are not scientific entities. As seen, these are similar problems to those approached by $\mathrm{G}$ Maxwell, but Quine does not stop here. Continuing with his metaphysical expurgation, Quine also attacks Peirce's idea of truth as unreachable limit ${ }^{2}$. "Limit", says Quine, must be applied exclusively to numbers (as is notion constructed from "near by"), applying it to objects such as theories is an incorrect extrapolation (Quine 1960, p. 23). This last critic hits precisely Popper's underlying ideas exposed in Logik der Forschung. Zur

\footnotetext{
${ }^{1}$ Addressed i.e., in Gower (2000), Demopoulos and Friedman (1989) and Massimi (2010). In the latter it is also addressed the structuralist perspective of scientists such as W. Pauli and N. Bohr.

2"Inquiry properly carried on will reach some definite and fixed result or approximate indefinitely toward that limit" (Peirce CP 1.485. [CP refers to the Collected Papers (19311958) of CS Peirce, C Hartshorne, P Weiss and AW Burks (eds.)])
} 
Erkenntnistheorie der modernen Naturwissenschaft (1934), one of the first texts focused on addressing scientific progress and rewrote in 1959 as The Logic of Scientific Discovery. In there, Popper exposes his theory of falsifiability which is supported on a notion of truth as an ideal ground on which to contrast theories, that will be recognised as a version of Peirce's in Conjectures and Refutations (1963, p. 229). Thus, Popper in 1963 endorses A Tarski's logico-semantic and metalinguistic formulation to restore the concept of "truth" against Quine's critic and to open science to an inventive capacity beyond its deductive systematicity (p. 221), as far as Tarski's system leads open the possibility of scientific examination by means of observational tests. So now, observational terms, if empirically adequate, can have truth content, so they can be part of a theory that can be contrasted with others equally constructed in terms of its verisimilitude, just as Popper wants. All in all, we see in Quine/Popper/Tarski the same problem we saw on G Maxwell: trying to know which entities can be justifiably invoked by science.

The previous example suggests that the possibility of dealing with the reality or not of theoretical entities is the general problem underlying the debate on scientific progress and scientific realism. This may seem obvious for some, but it is not redundant, as it implies a very concrete definition of "realism" far from the preceding debates in philosophy: A realist is one who accepts the existence of the entities postulated by science. Now, structural realism starts by endorsing this meaning of realism and accepts only the reality of the relationships between phenomena, and of no other entity. This gives us a basic insight on its notion of scientific progress, that is, unlike truthlikeness, problem-solving and knowledge accumulation proposals, it will need to endorse the existence of concrete entities, namely, structures. In the following section we will see why it would be necessary to commit to the reality of a structural nature (OSR) and not merely to structures as a descriptive tool (ESR) in order to justify progress.

\section{Formal Structural Realism: Epistemic Insufficiencies}

Ladyman, aware in What is Structural Realism (1998) that "the debate about how to characterise theories and their structure is of central concern" (Ladyman 1998, p. 415), defends precisely a semantic formalization for structural realism, as opposed to the insufficiency of G Maxwell's syntactic one ${ }^{3}$. This is partly because

\footnotetext{
${ }^{3}$ The semantic approach consists of an isomorphic structural representation of a theoretical system, so it is not an axiomatization of the theory itself. This allows the same formulation to be isomorphic to several theoretical representations, which is equivalent to committing itself to the structure of the theory independently of its ontology (the elements to which it refers). For a clear exposition of Ladyman's points on the semantic approach see French and Ladyman (1999). Here it is sufficient to say that Ladyman's semantic approach is mainly based on the contributions of the physicist $\mathrm{H}$. Weyl and his work on group theory in the theory of relativity and quantum mechanics (Ladyman 1998, Ladyman et al. 2007). According to group theory, objectivity can be explained in purely relational terms and without the need for substantiation, since it is the invariants under particular transformations that determine objectivity. Be that as it may, for our purpose it is not so necessary to expose Ladyman's semantic approach as to show his concerns about the formalization of structural realism.
} 
Ladyman relies on the critiques that Demopoulos (2003) and Demopoulos and Friedman (1985) did to G Maxwell's ideas. In fact, these authors saw in G Maxwell's re-adaptation of Russell 1927's project an approach that was already undermined by Newman (1928). In 1927, Russell left aside sense-data as a source of knowledge to focus on knowledge by description. Working on this, Russell used Ramsey's logical formalization, with which he translated theoretical terms into observational ones by transforming predicates into quantified variables that express type-relations. But Newman, in turn, considered that Ramsey/Russell were trivializing the empirical content of physics by reducing it just into its cardinality, so that two different sets with the same number of elements would be equal after being ramseyfied (Demopoulos 2003, Demopoulos and Friedman 1985), or as Ladyman phrases it: "the formal structure of a relation can easily be obtained with any collection of objects provided there are enough of them" (Ladyman 1998, p. 412). So, ramseyfication ends up requiring an observational or valuative criterion that decides on the importance of one relationship over another in order to prioritise between two cardinal-identical Ramsey formalisations (Newman 1928, p. 147), that is, requires something beyond what's formalized.

Following similar paths, we can see that even the semantic approach does not fully hold. Russell/Maxwell faced similar problems as Popper's truthlikeness even though the latter endorses the Tarskian logico-semantic approach. For while it is true that Popper's work consists in realizing that "the contents of the theories play an important role" (Popper 1963, p. 232), Popper defines the scientific relevance of this content in terms of its improbability (p. 229), that is, in terms of its unexpected resistance to being falsified. But as pointed out by both Miller and Tichý (1974), Popper's equation to contrast the relevance of two promising theories falls into a problem, for it is possible to add absurd, invented or false subtheories, but highly improbable, for the theory to gain in verisimilitude. So, although Popper is far from treating observations exclusively in terms of its cardinality, as for Popper the content is expressed by the natural language that then is formalized into a meta-language, there should be a prescientific criterion applied to the natural language regarding the appropriateness or not of the added subtheory. Thus, these logical formulations (both Russell's and Popper's) always require extra-logical knowledge about which theory we are talking about, so, for the moment, these approaches fail to offer solutions for problems raised by the form/content distinction ${ }^{5}$.

In a distinct way, Worrall (1989), another of the precursors of structural realism, insists on the mathematical capacity as an argument for structural realism, attributing this idea to $\mathrm{H}$ Poincaré. He considers that structural realism is the only perspective that can handle precisely two arguments related to scientific progress: gives an explanation for the non-miracles argument, according to which science predicts too well for all predictions be one miracle after another (Putnam 1975, p. 73); and avoids the pessimistic meta-induction argument, according to which, after

\footnotetext{
${ }^{4}$ Worrall and Zahar (2001) and Melia and Saatsi (2006) consider that it is possible to rehabilitate the ramseyfication.

${ }^{5}$ This and other problems of truthlikeness are trying to be overcome; see i.e., Niiniluoto (2003) and Oddie (2013).
} 
seeing that scientific theories are rejecting the previously postulated entities (ether, caloric, atomic model, etc.), we should induce that our present scientific entities will be rejected in the future (Laudan 1981). For Worrall it is obvious: neither empiricism, nor Quineans, nor classical realist, face both arguments completely, but overcoming them is as simple as accepting that what survives from one theory to another is the mathematical representation of nature's structure. With structural realism we can see, for example, the theoretical continuity between Fresnel elastic ether to Maxwell's electromagnetic field (Worrall 1989, p. 108), as these representations can be expanded and nuanced but are not abandoned even in scientific revolutions. So, following Worrall we could say that, contrary to the opinion of Lakatos (1970), it is not that scientific practice tends to protect the mathematical hard core of theories by ascribing the inadequacies to the peripheral particularities of the theory, but that this core does persist by its own.

However, Worrall, and we could include here Maxwell and also Votsis (2004, 2010), limit themselves to pointing out retrospectively the continuities between the mathematical relations of theories that has been successful in predicting, and after that, they make an act of faith regarding the accuracy of the whole theory. This means, in the first place, that the content of the theory is ignored; in fact in the case that the theory postulates the existence of certain entities, these would be accepted for practical purposes, just as it happened with Quine. And secondly, it is suggested that what is retained as true is the structure that survives theory change, but it is not clear whether the whole structure is retained or only the successful part of it. In any case, what they see, for example, is that "the equations derived from Maxwell's equations using continuity principles in the dielectric interface are formally identical [emphasis added] to those derived by Fresnel from his mechanical principles" (French and Saatsi 2006, p. 555). But the problem with such emphasis on the continuity of the representation leaves open the possibility of considering that there are other real components underlying nature that are inaccessible or inexpressible of which we only know or can know their structure; that is, these positions in the scope of formal structural realism end up in an ESR (Ladyman 1998, 2018).

That is the interpretation behind the claims that structural realism seems deemed to support a distinction between structure and nature (Psillos 1995), and that, therefore, science cannot go beyond formal knowledge. So, in order to account for the two scientific phenomena that Worrall reminds us of and to combat the vagueness of noumenical considerations of nature, or of scepticism, mysticism or constructivism, the only alternative seems to be to engage radically with the reality of structures. For this, the transcendence of mathematical knowledge and the structural reality they are describing must be established. To do this, one can begin, for example, by taking a step further in understanding the insights of contemporary physics and see that the history of scientific improvements, beyond the example of Worrall's Fresnel-Maxwell, shows the structural continuity from one theory to another independently of any evolution in the entities postulated by them (Ladyman 1998, p. 415) ${ }^{6}$. In doing so, structural realism will be committed

\footnotetext{
${ }^{6}$ "For example, it is widely held that the equation (known as Ehrenfest's theorem) $\mathbf{F}(\mathrm{krl})=$ $\mathrm{md} 2 \mathrm{krl} / \mathrm{dt} 2$ exhibits continuity between classical and quantum mechanics; it certainly has a
} 
to the existence of a structural nature (OSR), and therefore will go a step further than simply considering that a logic-semantic approach can be used scientifically to address physics in terms of structure as Ladyman $(1998,2007)$ and French and Ladyman (1999) continue to argue ${ }^{7}$. J Ladyman's project in Every Thing Must Go (2007), which he carries out together with D Ross, defends this position. They claim that neither objects nor intrinsic properties are ontologically fundamental. Even relationships do not presuppose related objects ("relata"), as Psillos (2001) criticised. As Ladyman argue, following Dennett's Real patterns (1991), objects are reified structures, that is, objects are patterns that are perceived on a relative scale for reasons of usefulness 8 , but in a closer look: "'it's relations all the way down" ${ }^{\prime}$. The structure is the ground; or the non-ground, the Abgrund. So, let us focus now on how Ladyman bases OSR.

\section{J. Ladyman and the commitment with the reality of the structures}

Let us present some key points of the conception that Ladyman exposes in Every Thing Must Go, understanding that with them he establishes an alternative justification for the structural realism with which he seeks to overcome the errors of his predecessors.

Ladyman titles his project in Every Thing Must Go of "Naturalized Metaphysics". Under it, he offers a series of considerations/principles that systematically justify each other and whose evidence evokes the realisation that "Structure is all there is" (2007 p. 130). We summarize these principles into three: 1) The consideration that the results of physics, specially quantum physics and relativity theory, are those that contribute more to the understanding of any other branch of science and thought, ("Primacy of Physics Constraint" or "PPC") (Ladyman 2007, §1.4); 2) The interdependence of contributions of scientific fields, albeit asymmetric towards physics ("Principle of Naturalistic Closure" or "PNC") (§4.5); and 3) The continuous hypothesis, according to which all phenomena belong to the same cosmos $(\S 1.5, \S 4.1)$. Assuming the consequences of one of these principles the others get justified, and OSR results to be the only coherent scientific approximation according to the latest contributions of physics and the applicability of the structural perspective to the rest of sciences. So to speak the

\footnotetext{
similar form to the equation $\mathbf{F}=$ ma. But the quantum equation has as its arguments the expectation values of Hermitian operators, whereas the classical equation features continuous real variables" (Ladyman 1998, p. 415).

${ }^{7}$ See note ${ }^{3}$

${ }^{8}$ This is a key point in Ladyman's conception. In Dennett's Real patterns (1991), patterns are projections that maximize information relative to the perceiver's ontological scale. Thus, they are projections, which means that could be otherwise if the needs or scale are different, but its effectiveness is real. In terms of philosophy of mind, Ladyman is subscribing a sort of instrumentalism; he does not endorse supervenience and his reductionism it wouldn't be a physicalism understood in classical terms. To all that, there is a strong Darwinism in this approach.

${ }^{9}$ Words by quantum physics theorist Saunders (2003). E Schrödinger, A Eddington, M Planck and $\mathrm{H}$ Weyl are other physicians referred by Ladyman.
} 
statement of OSR becomes the fourth principle of his naturalized metaphysics and its resultant thesis excludes the existence of objects, causal relationships between objects $^{10}$, natural kinds ${ }^{11}$ and intrinsic properties ${ }^{12}$, which are just patterns generated, in our case, at an anthropomorphic scale.

We observe, then, that for Ladyman these principles necessarily exclude scepticism as a philosophical position, since these principles allow him to speak of the "truth" of certain theories or statements; this is so for at least two reasons: one is given by the consequences of the principles and another is given by the revisionist character of the principles; and both point to his pragmatist and "verificationist" conception. In the first place, Ladyman excludes scepticism because the applications or practical consequences of his principles offer fruitful explanatory and predictive rules about nature, the object in question; these applications, on the one hand, legitimize the truth of the other principles (remember: 1) physics as a more explanatory science, 2) contribution of all sciences, 3) continuism, and 4) OSR) and on the other hand, they solve doubts of the scientific practice at the same time that they generate new problems and the need of deeper investigations ${ }^{13}$. With that, see Ladyman's parallelism with Peirce's pragmaticism maxim: "Consider what effects, that might conceivably have practical bearings, we conceive the object of our conception to have. Then, our conception of these effects is the whole of our conception of the object" (Peirce 1878b, p. 31). In short, for Ladyman there is truth knowledge, which in terms of metaphysical knowledge would be reflected in the knowledge of the principles. In fact, throughout the book, he refers to the "truth" of the theories and, consciously, not to the "approximate truth" of the theories, since he relates the latter to an objectifying worldview (Ladyman 2007, p. 84). For Ladyman there are no objects, but there are true structural formulations. However, we must stop for a moment at this explanation, since this use of the term "truth" should not confuse us: in Ladyman there is implicit a conception similar to that of Kant, Peirce and

\footnotetext{
${ }^{10} \S 5.1$

${ }^{11} \S 5.6$.

${ }^{12}$ Intrinsic properties presuppose the object that held such properties. So, what makes two logically identical individuals two and not one (Leibniz's Principle of Identity of the Indiscernible)? One candidate is its space-time location, but for different reasons in both quantum physics and general relativity theory, space-time does not exist independently of its components, and there's not emptiness in space-time. The other candidate is that there exists a principle of individuality transcendent to any intrinsic or extrinsic quality, a haecceities, according to Duns Scotus. Ladyman may consider this option due to one ambiguous case: bosons. Due to quantum entanglement a fermion and its antiparticle have a complementary electric charge relationship, they are complementary but asymmetrical (by this charge) so that makes them "a posteriori" discernible (weak PII), but this is not even the case with the bosons, whose antiparticle turns out to be absolutely identical as they do not have charge. It seems that there is no way to formalise the identity of a boson by reducing everything to structure. See $\S 3.1,3.2$.

${ }_{13}$ "As it appeases the irritation of doubt, which is the motive for thinking, thought relaxes, and comes to rest for a moment when belief is reached. But, since belief is a rule for action, the application of which involves further doubt and further thought, at the same time that it is a stopping-place, it is also a new starting-place for thought" (Peirce 1878b, p. 28).
} 
Popper about truth as an ideal limit and ultimate end of the inquiry ${ }^{14}$. Nevertheless, as I will also point out later, the ideal limit we attribute to Ladyman is not so much that of "truth" as that of the "unity" of the theories, which is strongly linked to the third of his principles. All in all, Ladyman would accept that knowledge is not total, but this does not make him a sceptic, since although true knowledge is not total, knowledge can still be justified, rational and predictive knowledge, that is, that knowledge could be not false and with the form of an educated guess.

The second reason why Ladyman can move away from scepticism help us to show one of the reasons why we prefer to treat his position as speculative and not as metaphysical or "naturalized metaphysical". We have already mentioned several times that for Ladyman, the principles are not justified because they are clearly and distinctly evident, but because they are coherent with the practical consequences of each other. Under this idea, we rely on what Meillassoux (2010) expresses against "dogmatic metaphysics", namely, that "to reject dogmatic metaphysics means to reject all real necessity, and a fortiori to reject the principle of sufficient reason" (Meillassoux 2010, p. 33). Thus, for Ladyman (2007), metaphysics and scepticism are comparable, since both start from the a priori assumptions of an entity that is the principle of reason of the other entities: in metaphysics this entity is considered known and in scepticism this entity is always unknown. But for Ladyman there is no such a priori; naturalized metaphysical knowledge is constituted as knowledge precisely through its practical consequences, because of its a posteriori. However, it can be argued that Ladyman seems to be conferring an a priori reality to an entity, namely, the homogeneous world, which would move away from Meillassoux's conception, who privileges the knowledge of the necessary contingency of it (Meillassoux 2010). But as far as we are concerned, Ladyman's world can also be seen as an asymptotic ideal or a transcendental illusion, just as Kant marked in his antinomies of pure reason. But we should not let pass that the homogeneity of Ladyman's world, in front of its possible discontinuity, can be considered one of the most debatable postulates of his theory. But be that as it may, he does not stop pretending to be coherent with his pragmatic and revisionist conception, that is, among other things, he does not stop pretending to be coherent with the insights of present physical theories.

Let us now turn to another feature of Ladyman's theory that is relevant to the OSR: according to the principles, scientific theories should be modal and not only real (Ladyman 2007, p. 123-). This is affirmed in contrast to van Fraassen's empirical constructivism and his criticism of structural realism, the thesis of empirical constructivism being the idea that we should only commit ourselves to what is empirically verifiable (van Fraassen 1980, p. 60); as can be seen, once again raising the problem of the scientifically observable/non-observable. For Ladyman, the modal does not refer to a metaphysics of possible worlds like that of D Lewis or S Kripke, but the modal must be understood as the possible, and the possible as the accessible. For Ladyman the human being is linked to a relative scale and to a technology and measuring devices that limit his observations. However, we can also have other ontological limits of access, as the Minkowski

\footnotetext{
${ }^{14}$ "The opinion which is fated to be ultimately agreed to by all who investigate, is what we mean by the truth" (Peirce CP 5.407).
} 
cone of light points out, for example, beyond which we cannot have access even in a possible sense. The limits of the possible are then a question of information connectivity (p. 278-), and the limits of research are marked by this. Therefore, realism is no longer linked only to what is observable precisely in other pragmatic terms ${ }^{15}$.

Finally, to finish with this general exhibition of Ladyman's project we want to mention one last aspect that ends in an open question. We have seen that Ladyman argues for the substantiation of the structure: structure now has formal properties and is at the same time its content. However, given that this structure is represented in theories in a mathematical way, it all seems that we should consider mathematical entities as real, in a Platonic or Pythagorean sense and as authors such as A Badiou and M Tegmark maintain or as Lewis exposed (1993). In an interview for Collapse, Ladyman answers to this question reflecting his principles: "Our metaphysics is directly motivated by the actual content of physics, and our review of the latter significantly undermines the distinction between mathematical and physical-nomological structure" (Ladyman [Collapse vol. V] 2009, p.166).

\section{Scientific Practice according Ladyman: Verificationism}

Anti-sceptical optimism, revisionist methodology and the modal aspect of the OSR are three other characteristic notes with which to attempt, along with the three principles, to extract a conception of scientific progress in line with structural realism. But before formulating a definition of this progress, we lack a last clarification regarding what Ladyman understands by scientific practice.

In Every Thing Must Go Ladyman states that the three principles are embodied by the scientific institutions, so that they show an epistemic superiority compared to other kind of knowledge mainly due to its process of revisability and iteration of critical filters (Ladyman 2007, p. 29); this is what Ladyman calls "verificationism" (which is the only one of his ideas that he attributes to Peirce (Ladyman 2007, p. 29). In light of this, we would like to make a remark here. Ladyman believes that scientific institutions already act consistently with the principles. But we refrain from believing that such a claim of scientific "bona fide" is justified. In fact, in an interview for Collapse (2009), Ladyman is asked about this point due to the fact that, paradoxically, Ladyman, is in clear favour of the quantum gravity theory, and he even suggest approximation to the Everett's interpretations against the Copenhagen one, and held the importance of developing Bohmian mechanics against classical quantum mechanics, all in all, Ladyman shares approximations which are strongly disregarded in scientific institutions in comparison, for example, to string theory or M-theory: His answer on why then to think that institutionalized scientific practice endorses the principles is elusive. So, we are inclined to say that institutional scientific practices do not necessary endorse this

\footnotetext{
${ }^{15}$ We repeat a quote from Peirce, to emphasize the aspect of Ladyman that we have just commented: "Consider what effects, that might conceivably [emphasis added] have practical bearings, we conceive the object of our conception to have. Then, our conception of these effects is the whole of our conception of the object" (Peirce 1878b, p. 31).
} 
bona fide nor necessarily embody the three principles, so we would like to substitute Ladyman's is for a should. This will also serve to mark the normative and non-descriptive character of the definition of scientific progress.

Regardless of this point, what is important to note about Ladyman's verificationism is that he argues that scientific practice takes (or should take) a pragmatic attitude, that is, scientific institutions should only work with theories that fall under the modal scope (and see that we can say "modal" or structural/ mathematical/informational). That is, the criterion is neither empirical nor metaphysical, but speculative, or parallel to Peirce, neither inductive nor deductive, but abductive (Peirce 1878a). This form of speculation and abduction is the only conception that offers hypothesis with consequences, empirically treatable or not, that can appear anywhere in the scientific spectrum, in any scientific field, therefore, following principles 1), 2) and 3).

But be that as it may, with his perspective on scientific practice, Ladyman seems to reflect a very intriguing aspect of the history of the philosophy of science. It seems that it is no longer a question of justifying the truth or the adequacy of science on the basis of formal corroboration, nor is it enough to relativize it according to sociological characteristics (as Kuhn makes us reflect upon), but it seems that Ladyman supports basing the correctness of science on the virtues and good faith of scientists, namely, basing the rigor of science on honesty, openmindedness, transparency, etc. In short, what Sosa $(1980,2007)$ calls "virtue epistemology" and which returns to Socrates. We find this thesis very interesting, but we will keep the discussion in parentheses and, on the contrary, argue that basing correction on virtuosity does not imply defending the idea that the subject contains some inherent values that make it a sort of guarantor of epistemological correction. On the contrary, we will read this bona fide practice, which we still think is a very important leg for scientific progress, as a necessary consequence of pragmatism and speculation. Thus, we understand that these values are not values in themselves, they are like empty forms, and they acquire meaning in the light of the conclusions of the three principles. That is, values like open-mindedness, sincerity, rigor and correction can be considered as translations of methodological conclusions such as research on what is possible or modal and not only on what is current or empirical or visible, importance of revisability, recognition of these revisions, place coherent and practical limits on our research, generate knowledge in the form of educated conjectures... in short, maxims that are not a priori but are promoted and justified by the principles and by the consequences of the principles.

\section{Progress in OSR and the Principle of Continuity}

We already have enough ingredients to infer a definition of scientific progress in line with the OSR.

At this point, it is worth quoting a claim that appears at the beginning of Ladyman's book anticipating many of his concepts that we already described and paving the path to a "metaphysical claim" such as "Structure is all there is": 
"Any new metaphysical claim that is to be taken seriously should be motivated by, and only by, the service it would perform, if true, in showing how two or more specific scientific hypotheses jointly explain more than the sum of what is explained by the two hypotheses taken separately, where a "scientific hypothesis" is understood as an hypothesis that is taken seriously by institutionally bona fide current science" (p. 30).

"Structure is all there is" can be successfully applied to two separate scientific theories or to two scientific fields and will show them a profound knowledge, namely its fundamental shared basis together with the possibility of explaining its mathematical or its nomological interdependence. Now, taking the contributions of our previous discussion, this last idea, which is not further developed by Ladyman, applied to the construction of scientific hypothesis gives us the cornerstone for the definition of scientific progress according to structural realism: (Ontic) structural realism measures scientific progress according to the aim of epistemological continuity being equal to ontological holism. Or what is the same, according to OSR, a theory would make scientific progress compared to another if it establishes an informational connection between patterns, where "patterns" can refer either to theories or phenomena. Note that as disconnection is for OSR not a justified idea, the only alternatives for science to progress is to either connect two patterns or to connect a pattern to a yet unknown and epistemologically unconnected pattern. Thus, aiming at unity is not the same as aiming at simplicity. All in all, one conclusion already anticipated in the previous section is that ontological holism, phrased primarily in the continuum principle, plays the homologue role of "truth" in the truthlikeness approach on scientific progress. However, ontological holism is not a principle formally based as truth for the truthlikeness approach, and neither it is considered as an a priori statement, but rather it is based on a speculative basis: ontological holism is the result of the interdependence of, on the one hand, a pragmatic rationality and, on the other, the successfulness of a modal approach according to empirically as well as mathematically verified structural analysis, as is represented in the insights of contemporary physics.

And leaving aside his continuist conception, we can go even deeper into what we mean by speculative. After all, what is special about our suggested formulation of scientific progress of OSR and what distinguish it from the other main accounts on progress matches perfectly with more reasons of why do we use the term "speculative":

a) As by speculative we also refer to daring to go beyond formalising just observational terms, and also to even holding the substantiality of theoretical ones (Opposed to truthlikeness) ${ }^{16}$.

b) As by speculative we also refer to going beyond anthropomorphic and utilitarian problems. Progress is not just the variegated application of known laws to supposed different phenomena or objects, and even less to the generation of these. Knowing how to solve a problem, in some cases,

\footnotetext{
${ }^{16}$ Paradigmatically held by Popper (1963) and Niiniluoto (1977), but also by van Fraassen (1980) and Saatsi (2019).
} 
may contribute nothing to the global understanding of reality. Thus, we can say that whereas progress entails more prediction, more predictions does not entail more progress. (Opposed to problem-solving and to accumulation of knowledge) ${ }^{17}$.

Given this, and as during this brief essay we have already been dealing with the separation of Ladyman's position from the classic truthlikeness formulations, let's say one last thing in reference to $\beta$. As Ladyman explicitly states to follow non-utilitarian principles at the beginning of his book:

"What we importantly wish to exclude that will not be obvious from anything said so far, however, are research projects that are primarily motivated by anthropocentric (for example, purely engineering driven) ambitions, as opposed to ambitions anchored around attempts to determine the objective structures in nature." (Ladyman 2007, p. 36)

Previously, we indicated that Ladyman's project cannot be understood completely, or at least without nuances, as a properly speculative project like the one that Meillassoux paradigmatically represents. Since, as we have mentioned, according to Meillassoux, Ladyman seems to consider in metaphysical terms the homogeneous world as the one and absolutely necessary entity. In the same vein, Ladyman's conception cannot be understood either as purely practical or consequentialist. It is, as in the difference with Meillassoux's notion of speculation, the thesis of the ideal continuum that rejects such anthropocentrism, as well as the attempt to abandon correlationism ${ }^{18}$. Such an ideal integrated by Ladyman's pragmatism, makes clear that pragmatism is a mechanism for resolving conflicts by understanding the truth and sense of a thesis by means of its practical consequences ${ }^{19}$, but pragmatism does not prescribe what kind of ends should be pursued, and even less does it establish that these purposes must be utilitarian. In Ladyman, then, there is a pragmatism combined with some ideas that we consider speculative. In fact, our thesis is that we can extract a formulation of scientific progress according to the OSR, thanks to the combination of speculation and pragmatism of Ladyman's theory.

It seems opportune then to finish this essay commenting briefly on Ladyman's continuist conception, since, although it may seem coherent with the whole of his

\footnotetext{
${ }^{17}$ The former is held by Kuhn (2012) and Laudan (1981), the latter by Barnes (1991) and Bird (2008).

${ }^{18 "}$ "Correlationism" for Meillassoux includes all those philosophies that, establishing a relationship between subject and object, do not allow understanding one without the other. That is, this relationship, far from establishing conditions and motivations to knowledge, limits it. As far as we are concerned here, correlationism does not consider being able to know the world but just the subject knowing it. If this is one of the basic Kantian theses, Meillassoux calls it "correlationism" understanding that it is a whole philosophical conception present in authors such as M Heidegger, L Wittgenstein or M Merleau-Ponty. In fact, the book we are quoting, After the finitude, is an argument against this correlationist prison, showing that it is possible to know something about the external world independently of the subject.

${ }^{19}$ "Beliefs are distinguished by the different modes of action to which they give rise" (Peirce 1878b, p. 29).
} 
system, it does not cease to seem to us the fundamental point of his theory and a source of discussion. It is Meillassoux himself who takes from D Hume the scepticism regarding the absolute necessity of the temporal continuity of the physical laws, and with that, he launches a criticism against "the principle of the uniformity of nature" 20 . For Meillassoux the continuist hypothesis if it is not a metaphysical postulate is then based on an erroneous probabilistic analogy that insinuates that there is continuity and stability of the physical laws because induction shows us how infinitely improbable it is that the opposite occurs. In view of this, Meillassoux, taking up G Cantor's ideas, assures that this calculation is impossible to carry out unless a complete and absolute world is already presupposed as the denominator of the operation ${ }^{21}$. On a completely different line, the continuum hypothesis was also questioned by Plato. In The Sophist, an ontological discontinuity was argued in spatial terms with his famous epistemological principle of symploké: "if everything were linked to everything we could know nothing" (Platon 1992, 259e). "For if in order to know something, there was always the need to know something prior, and, even earlier, something previous, and thus ad infinitum, then we could not know anything" (Sierra 2000, [54: symploké]) $)^{22}$, which far from being understood as a principle of fallibilism, as we will mention that it is for Peirce, can be understood as the reason why there are different sciences dedicated to different supervenient phenomena.

Then, grant us to think that Ladyman's position may not be totally speculative in Meillassoux's terms, for although he shares many traits with him, we consider that a deeper discussion is pertinent about whether the considered Ladyman's ontological holism or continuist principle adheres to the speculative gesture or whether it introduces a metaphysical element. In any case, this does not take away from the fact that Ladyman's approach and the OSR's definition of scientific progress can be considered speculative in accordance with the characteristics we have been explaining. And the same is true of pragmatism. As we have mentioned, the aspiration to the continuist hypothesis as an ideal of progress is a challenge to utilitarianism or practicality, but not to pragmatism. And it is precisely in Peirce, a pragmatist par excellence, that we find support for the hypothesis of the continuity of the world (including the continuity between matter and mind) in what he called synechism: "Synechism is that tendency of philosophical thought which insists upon the idea of continuity as of prime importance in philosophy and, in

\footnotetext{
${ }^{20}$ "But only the time that harbours the capacity to destroy every determinate reality, while obeying no determinate law - the time capable of destroying, without reason or law, both worlds and things - can be thought as an absolute. Only unreason can be thought as eternal, because only unreason can be thought as at once anhypothetical and absolute. Accordingly, we can say that it is possible to demonstrate the absolute necessity of everything's non-necessity. In other words, it is possible to establish, through indirect demonstration, the absolute necessity of the contingency of everything" (Meillassoux 2010, p. 62).

${ }^{21}$ "Thus, probabilistic reasoning is conceivable on condition that it be possible to conceive a totality of cases within which one can then calculate frequencies by determining the ratio of the number of favourable cases to the number of possible cases. If you revoke the notion of a set of cases and the idea of a total-universe from whence the events submitted to analysis are drawn, then aleatory reasoning becomes meaningless" (p. 102).

${ }^{22}$ Our translation.
} 
particular, upon the necessity of hypotheses involving true continuity" (Peirce 1902, p. 354).

We cannot go into detail in Peirce's argument about synechism, but in general terms, Peirce considers that past ideas reappear or influence present ideas as long as they are not completely past. Ideas are infinitesimally linked (Peirce 1892, p. $341)^{23}$, in turn, ideas reflect sensations (p. 344). And sensations are chains of stimuli reflecting parts of the infinitesimal infinitude of space ${ }^{24}$. We see then that in synechism the element of infinitesimal is present, as in Plato, but this time with a conclusion totally opposite to the one of Plato and that has repercussions on the model of scientific inquiry. In Peirce it is that ideal and absolute limit which, as we saw also in Ladyman, far from inducing to the relative scepticism or discontinuism in a Platonic way, it is an optimism that takes the form of fallibilism, of a wellconstructed science that is always to be improved a bit more as far as it is structures all way down. Continuity, then, says Peirce, requires supporting, for example, the truth of the asymptotic value of number $\pi$, "the principle of continuity is the idea of fallibilism objectified (Peirce 1902, p. 356).

$\mathrm{Be}$ that as it may, we insist that the discussions on the coherence of the principle of continuity, or its justification or not in the light of the contributions of physics goes beyond the present essay. But we do want to point out that in its origin, such a thesis never supposed a metaphysical thesis, as clearly presented by Peirce himself: "Synechism is not an ultimate and absolute metaphysical doctrine; it is a regulative principle of logic, prescribing what sort of hypothesis is fit to be entertained and examined" (Peirce 1902, p. 355). If we trust Peirce, and Ladyman, we should say that if the continuist thesis is maintained or not, it is not because it is given over by metaphysics. On the contrary, to hold or not to hold the principle of continuity wrongly must be the fault of the "bona fide" of the current scientific practice. By correctly applying speculative and pragmatic conclusions we would get rid of these doubts, which for Ladyman is clear in favour of this principle and consequently of the truth of the OSR. However, if the latter were contradicted, the pragmatic and speculative principles will have led us to take another step towards progress.

\section{Conclusions}

The present text has attempted to provide a hypothetical formulation of scientific progress in line with structural realism. The first task in developing this formulation has been to offer a tangential review of the literature on structural realism in order to show that its problems are closely linked to the debate on

\footnotetext{
${ }^{23}$ "This infinitesimally spread-out consciousness is a direct feeling of its contents as spread out" (Peirce 1892, p. 341).

24 "Since space is continuous, it follows that there must be an immediate community of feeling between parts of mind infinitesimally near together" (Peirce 1892, p. 355). Outer space that is nothing but habituated ideas. "the reaction between mind and matter would be of no essentially different kind from the action between parts of mind that are in continuous union, and would thus come directly under the great law of mental association" (Peirce 1902, p. 353).
} 
scientific progress. We find its connection in a similar concern for how to account for the existence of theoretical entities, a problem thus made explicit in the philosophy mainly by the analytic philosophers of its context. Then, we have seen that structural realism could not be defended trough syntactic formulation and was also insufficient if it sustained semantic formulations that were accompanied by scepticism or noumenism, that is, what is called epistemological structural realism (ESR), according to which science knows structures, but there can always be something beyond those structures.

Thus we arrived at the work of J Ladyman in Every Thing Must Go, In there he offers a defence of ontic structural realism (OSR), which claims that structures are not only what we can know of reality but that structures are reality. Which such a claim it is possible to respond to the epistemological problems of the philosophy of science regarding the justification of theoretical entities and tries to overcome the inconsistencies of his structural realist predecessors. Its conception for arguing for OSR is pragmatist because it legitimizes knowledge in accordance with the practical consequences of other knowledge and clears up any hypothesis whose consequences are not conceivable. Furthermore, Ladyman is akin to the speculative elements with which we have defined progress: rational justification but not a priori, confidence in access to truths about the world, consideration of limits but not anthropocentric ones. In this way, his work is the basis of our proposal to define scientific progress in accordance with structural realism and which reads as follows: (Ontic) structural realism measures scientific progress according to the aim of epistemological continuity being equal to ontological holism. We have called this definition "speculative" influenced by the terminology of Q Meillassoux, since we maintain that both the content and the reason for its formulation respond to speculative criteria, and it is these same criteria that make it special with respect to other definitions of scientific progress that are formulated under the approaches of truthlikeness, problem-solving or accumulation of knowledge.

Along with this, we have found that Ladyman's work shows ideas already exposed by CS Peirce. With this we want to incite a reflection on the relevance of Peirce in contemporary pragmatist and speculative positions. Finally, we can draw two final conclusions: on the one hand, that the continuist hypothesis is still an incipient theme in the philosophy of science and, specifically, with Ladyman could be introduced in the debate on scientific progress. And finally, and perhaps above all, we think that through Peirce, Ladyman and Meillassoux we can describe scientific progress without taking into account utilitarian and anthropocentric considerations, but at the same time, without falling into metaphysical statements or logical formalisms. We believe that more discussion about this definition of progress is convenient to clarify how we catalogue progress in our epoch. Finally, the OSR's maxim of progress encourages inquiry along the lines of Poincare in his fascination with the cosmos per se: "Would it be proper to ask what is the good of accumulating so much wealth and whether, to get time to acquire it, we are to neglect art and science, which alone give us souls capable of enjoying it" (Poincaré 1905, p. 93). 


\section{References}

Barnes E (1991) Beyond verisimilitude: a linguistically invariant basis for scientific progress. Synthese 88(Sep): 309-339.

Bird A (2008) Scientific progress as accumulation of knowledge: a reply to Rowbotttom. Studies in History and Philosophy of Science, Part A 39(2): 279-281.

Demopoulos W (2003) Russell's structuralism and the absolute description of the world. In N Griffin (ed.), The Cambridge Companion to Bertrand Russell, 392-419. Cambridge: Cambridge University Press.

Demopoulos W, Friedman M (1985) Critical notice: Bertrand Russell's The Analysis of Matter: its historical context and contemporary interest. Philosophy of Science 52(4): 621-639.

Dennett D (1991). Real patterns. Journal of Philosophy 88(1): 27-51.

French S, Ladyman J (1999) Reinflating the semantic approach. International Studies in the Philosophy of Science 13(2): 103-121.

French S, Saatsi J (2006) Realism about structure: the semantic view and non-linguistic representations. Philosophy of Science 73(5): 548-559.

Gower B (2000) Cassirer, Schlick and "Structural" realism: the philosophy of the exact sciences in the background to early logical empiricism. British Journal for the History of Philosophy 8(1): 71-106.

Kuhn T (2012) The structure of scientific revolutions. $4^{\text {th }}$ Edition. Chicago: University of Chicago Press.

Ladyman J (1998) What is structural realism? Studies in History and Philosophy of Science Part A 29(3): 409-424.

Ladyman J (2009) Who's afraid of scientism? Interview with James Ladyman. In D Veal (ed.), Collapse V, 135-185.

Ladyman J (2018) Structural realism. In E Zalta (ed.), The Stanford Encyclopedia of Philosophy. Winter 2018 Edition.

Ladyman J, Ross D, Collier J, Spurrett D, Spurrett D, Collier JG (2007) Everything must go: metaphysics naturalized. Oxford: Oxford University Press.

Lakatos I (1970) Falsification and the methodology of scientific research programmes. Reprinted in JA Kourany (ed., 1986) Scientific Knowledge: Basic Issues in the Philosophy of Science. Belmont, CA: Wadsworth, 170-196.

Laudan L (1981) A confutation of convergent realism. Philosophy of Science 48(1): 19-49.

Lewis D (1993) Mathematics is megethology. Philosophia Mathematica 1(1): 3-23.

Massimi M (2010) Structural realism: a neo-Kantian perspective.In Scientific Structuralism, 1-23. Dordrecht: Springer.

Maxwell G (1962) The ontological status of theoretical entities. In H Feigl, G Maxwell (eds.), Scientific Explanation, Space, and Time, volume 3, Minnesota Studies in the Philosophy of Science, 3-15. Minneapolis: University of Minnesota Press.

Maxwell G (1970) Structural realism and the meaning of theoretical terms. In S Winokur, M Radner (eds.), Analyses of Theories and Methods of Physics and Psychology. Minnesota Studies in the Philosophy of Science 4: 181-192.

Meillassoux Q (2010) After finitude: an essay on the necessity of contingency. Bloomsbury Publishing.

Melia J, Saatsi J (2006) Ramseyfication and theoretical content. The British Journal for the Philosophy of Science 57(3): 561-585.

Newman MHA (1928) Mr. Russell's causal theory of perception. Mind n.s(37): 137-148 
Niiniluoto I (1977) On the truthlikeness of generalizations. In RE Butts, J Hintikka (eds.), Basic Problems in Methodology and Linguistics, 121-147. Dordrecht, The Netherlands: Reidel.

Niiniluoto I (2003) Content and likeness definitions of verisimilitude. In J Hintikka (ed.), Philosophy and Logic: In Search of the Polish Tradition, 27-36. Dordrecht, The Netherlands: Kluwer.

Oddie G (2013) The content, consequence and likeness approaches to verisimilitude: compatibility, trivialization, and underdetermination. Synthese 190(9): 1647-1687.

Peirce CS (1970) [1878a] Deducción, inducción e hipótesis. (Deduction, induction and hipothesis). Buenos Aires: Aguilar, 65-90.

Peirce CS (1955) [1878b] How to make our ideas clear. In J Buchler (ed.), Philosophical Writings of Peirce, 23-41. Nova Iorque: Dover Publications.

Peirce CS (1955) [1892] Law of mind. In J Buchler (ed.), Philosophical Writings of Peirce, 339-353. Nova Iorque: Dover Publications.

Peirce CS (1955) [1902] Synechism, fallibilism and evolutionism. In J Buchler (ed.), Philosophical Writings of Peirce, 354-360. Nova Iorque: Dover Publications.

Peirce CS (1931-1958). Collected papers, volumes 1-8. In C Hartshorne, P Weiss and AW Burks (eds.) Cambridge, MA: Harvard University Press.

Platon (1992) Diálogos, V (Parménides, Teeteto, Sofista, Político). (Dialogues, V (Parmenides, Theaetetus, Sophist, Statesman)). Madrid: Gredos.

Poincaré JH (1947) [1905] El valor de la ciencia. (The value of science). Espasa-Calpe.

Popper K (2005) [1934, 1959] The logic of scientific discovery. Routledge.

Popper KR (1963) Conjectures and refutations. New York: Routledge.

Psillos S (1995) Is structural realism the best of both worlds? Dialectica 49(1): 15-46.

Psillos S (2001) Is structural realism possible? Philosophy of Science 68(Supplementary Volume): S13-S24.

Putnam H (1975) Mathematics, matter and method. Volume 1 of Philosophical Papers. Cambridge: Cambridge University Press.

Quine WV (1951) Main trends in recent philosophy: two dogmas of empiricism. The Philosophical Review 60(1): 20-43.

Quine WVO (2013) [1960] Word and object. MIT Press.

Russell B (1927) The analysis of matter. London: Allen \& Unwin.

Saatsi J (2019) What is theoretical progress of science? Synthese 196(2): 611-631.

Saunders S (2003) Critical notice: Cao's "The Conceptual Development of $20^{\text {th }}$ Century Field Theories". Synthese 136(Jul): 79-105.

Sierra PG (2000) Diccionario filosófico. Manual de materialismo filosófico. Una introducción analítica. (Philosophical dictionary. Handbook of philosophical materialism. An analytic introduction). Oviedo: Pentalfa.

Sosa E (1980) The raft and the pyramid: Coherence versus foundations in the theory of knowledge. Midwest Studies in Philosophy 5(1): 3-25.

Sosa E (2007) A virtue epistemology. Oxford: Oxford University Press.

Tichý P (1974) On Popper's definitions of verisimilitude. The British Journal for the Philosophy of Science 25(2): 155-160.

van Fraassen B (1980) The scientific image. Oxford: Oxford University Press.

van Fraassen (2006) Structure: its shadow and substance. The British Journal for the Philosophy of Science 57(2): 275-307.

Votsis I (2004) The epistemological status of scientific theories: an investigation of the structural realist account. PhD Thesis. London: London School of Economics.

Votsis I (2010) Structural realism: continuity and its limits. In Scientific Structuralism, 105-117. Dordrecht, The Netherlands: Springer.

Worrall J (1989) Structural realism: the best of both worlds? Dialectica 43(1/2): 99-124. 
Worrall J, Zahar E (2001) Ramseyfication and structural realism. Appendix IV in E Zahar (ed.), Poincaré's Philosophy: From Conventionalism to Phenomenology. Chicago and La Salle (IL): Open Court. 
